Disclosure of Interest: None declared

DOI: 10.1136/annrheumdis-2018-eular.6568

\section{AB0411 2 RISK OF REACTIVATION OF HEPATITIS B VIRUS IN RHEUMATOID ARTHRITIS PATIENTS WHO RECEIVED LONG-TERM LOW DOSE CORTICOSTEROID THERAPY}

W. Jeong ${ }^{1}$, J. Kim ${ }^{1}$, E.-J. Park ${ }^{2}$, B.-C. Song ${ }^{3} .{ }^{1}$ Rheumatology, Jeju National University Hospital, Jeju-Si; ${ }^{2}$ Rheumatology, National medical center, seoul; ${ }^{3}$ Hepatology, Jeju National University Hospital, Jeju-Si, Korea, Republic of Ireland

Background: It is well known that the use of corticosteroids results in increased viral replication and elevated ALT in patients with hepatitis B virus. The use of high dose corticosteroids for more than 4 weeks usually results in hepatitis worsening after cessation of steroids. However, few studies have investigated the effect of low dose corticosteroids on hepatitis B virus (HBV) reactivation.

Objectives: The aim of this study is to investigate the reactivity of HBV in rheumatoid arthritis (RA) patients treated with long term low dose corticosteroids and its risk factor.

Methods: Patients with HBsAg positive who were diagnosed with RA and who received prednisolone of less than $10 \mathrm{mg} /$ day over four weeks and immunosuppressive agent were selected at four university hospitals in South Korea between June 1996 and March 2017. Medical records and laboratory data were retrospectively analysed and multivariate analysis was performed.

Results: One hundred forty five patients were included in the study and 26 (17.9\%) patients were reactivated with HBV. Mean age at diagnosis of RA was 50.7 years and $41(28.3 \%)$ patients were male. Baseline characteristics including sex, age and laboratory findings at diagnosis of rheumatoid arthritis were not significantly different in patients with HBV reactivation compared to those without $\mathrm{HBV}$ reactivation. The average daily dose of prednisolone was $3.65 \pm 2.77 \mathrm{mg}$ and the mean duration of prednisolone was $5.11 \pm 5.05$ years and the average cumulative dose of prednisolone was $5821.6 \pm 7021.3 \mathrm{mg}$. Eleven $(42.3 \%)$ of $26 \mathrm{HBV}$ reactivated patients were reactivated within one year after prednisolone administration and the period from the start of prednisolone administration to the reactivation was $4.08 \pm 5.77$ years on average. The duration of prednisolone administration, mean daily dose of prednisolone, and cumulative prednisolone dose and administration of methotrexate, tacrolimus, tumour necrosis factor inhibitor and hydroxychloroquine did not significantly affect HBV reactivation in both univariate and multivariate analyses. However, the administration of leflunomide showed a significant difference in the reactivation of HBV (adjusted odd ratio 3.76; $\mathrm{p}=0.04$ )

Conclusions: The hepatitis B virus can be exacerbated by spontaneous viral reactivation, so it is difficult to conclude that hepatitis is caused by the administration of steroids. In this study, the administration of low-dose steroids did not affect the reactivation of HBV. However, leflunomide increased the risk of HBV reactivation when the effects of other disease modifying antirheumatic drug (DMARD) were corrected. Therefore, a prospective study is needed to evaluate the effect of DMARDs on HBV reactivation in the long - term administration of low - dose corticoststeroids in RA patients.

\section{REFERENCES:}

[1] Tur-Kaspa R, Burk RD, Shaul Y, et al. Hepatitis B virus DNA contains a glucocorticoid-responsive element. Proc Natl Acad Sci USA 1986:83:1627-31

[2] Di Bisceglie AM, Lok AS, Martin P, et al. Recent US Food and Drug Administration warnings on hepatitis $B$ reactivation with immune-suppressing and anticancer drugs: Just the tip of the iceberg? Hepatology 2015:61:703-11

[3] Bae JH, Sohn JH, Lee HS, et al. A fatal case of hepatitis B virus (HBV) reactivation during long-term, very-low-dose steroid treatment in an inactive HBV carrier. Clin Mol Hepatol 2012;18:225-8.

Disclosure of Interest: None declared

DOI: 10.1136/annrheumdis-2018-eular.4450

\section{AB0412 DYNAMICS OF QUANTITATIVE BODY COMPOSITION INDICES BY THE METHOD OF DUAL-ENERGY X-RAY ABSORPTIOMETRY (DRA) IN PATIENTS WITH EARLY RA DEPENDING ON THE ACHIEVED ACTIVITY OF THE DISEASE}

Y. Gorbunova, T. Popkova, L. Kondratyeva, A. Smirnov, E. Nasonov. Nasonova Research Institute of Rheumatology, Moscow, Russia, Moscow, Russian Federation

Background: Adipose tissue an active endocrine organ. In pts with RA the redistribution of body fat mass. Using BMI and WC do not allow to distinguish between fat and lean (muscle) mass. Performing dual-energy X-ray absorptiometry allows to specify the quantitative composition of the body(mass of adipose tissue and muscle) in pts with early RA

Objectives: to compare the indicators of the quantitative composition of the body in groups of RApts with different disease activity before and after the appointment of therapy.

Methods: included 37pts with early RA(ACR/EULAR2010), 57 [46.5, 62] yrs, duration of disease $6[5.5,15.5] \mathrm{mths}$, IgMRF seropositive antiCCP, with high RA activity(DAS285.5 [5.1,6], SDAI 32.4 [22.4, 42], CDAI 29 [19.7, 39.5]). After inclusion in the study, all pts started receiving MTX 10 [10-15 mg/week), after 12 weeks, with ineffective MTX, ADA $40 \mathrm{mg} /{ }^{2}$ weeks was prescribed. The quantitative composition of the body was determined initially and after $6 \mathrm{mths}$ by means of DXA using the apparatus HOLOGIC,analysing the following parameters:the total, of fat and lean mass.

Results: By the 24th week of therapy, $13(35 \%)$ pts with earlyRA received combined therapy(ADA, MTX), 24 (65\%) pts with RA monotherapy MTX. Depending on the activity of RA(DAS28)by the 24th week of therapy, pts are divided into 2groups: I $(n=18)$ pts with remission/low activity, $I I(n=19)$ with moderate/high RA activity (table 1). Initially, the groups differed in fat mass:this index was higher in the group of pts with moderate/high activity persisting, compared with the group of pts with remission/low activity of RA:30.2 kg versus $19.4 \mathrm{~kg}$. In the I group of pts before the treatment and after $6 \mathrm{mth}$ of therapy, a statistically significant decrease in muscle mass was observed:from $45.2 \mathrm{~kg}$ to $41.6 \mathrm{~kg}$. A decrease in the mass of adipose tissue after 24 weeks of therapy was noted in the Ilgroup of pts with RA from $30.2 \mathrm{~kg}$ to $28.2 \mathrm{~kg}$. The difference in the indices between the groups by the 6 month of therapy was noted for the mass of adipose tissue. This composition of the body score was also higher in pts with moderate and high RA activity, compared to the group of pts with remission/low RA activity: $28.2 \mathrm{~kg}$ versus $18.9 \mathrm{~kg}$ $(\mathrm{p}<0.05$ in all cases).

Abstract AB0412 - Table 1

\begin{tabular}{lcccccc}
\hline & \multicolumn{2}{c}{ Group I(n=18)Remission/low activity } & \multicolumn{3}{c}{ GrouplI(n=19)Medium/high activity } \\
\cline { 2 - 7 } & 0 & 24 weeks & $\Delta$, & 0 & 24 weeks & $\Delta$, \\
& & & $\%$ & & & $\%$ \\
\hline Fat mass, kg & 19,4 & 18,9 & -3 & 30,2 & 28,2 & -7 \\
& {$[15,8 ; 25,9]^{* *}$} & {$[16,4 ; 24,3]^{\star \star *}$} & & {$[20,7 ; 37,6]$} & {$[22,7 ; 40,2]^{*}$} & \\
Lean mass, & 45,2 & 41,6 & -8 & 42,9 & 44,2 & +3 \\
kg & {$[38,9 ; 54,4]$} & {$[38,6 ; 48,4]^{\star}$} & & {$[38,9 ; 54]$} & {$[40,1 ; 55,4]$} & \\
Total weight, & 70 & 64,9 & -7 & 72,8 & 74,7 & +3 \\
kg & {$[58 ; 80,8]$} & {$[59,5 ; 81]$} & & {$[60 ; ; 102]$} & {$[64 ; 97,9]$} & \\
BMl, kg/m ${ }^{2}$ & $23,4[21,5 ; 27,5]$ & 23,8 & +1 & 26,8 & 26,0 & -2 \\
& $* \star$ & {$[20,2 ; 26,5]$} & & {$[22,8 ; 34,6]$} & {$[23,3 ; 34,3]$} & \\
\hline
\end{tabular}

${ }^{*} \mathrm{p}<0,05$ reliability of differences in factors before treatment and after $6 \mathrm{mth}$ (Wilcoxon); ${ }^{* *} \mathrm{p}<0.05$ differences in baseline values in Groups I and II(Mann-Whitney test);

${ }^{* * *} \mathrm{p}<0.05$ difference in the indices between the groups by the $6 \mathrm{mth}$ of therapy; $\Delta \%$ the difference between the indices between the groups by the $6 \mathrm{~m}$ th of therapy.

Conclusions: pts with RA who achieved Igroup after 6 mths of therapy initially had a smaller volume of adipose tissue, compared with pts with moderate and high RA activity. Despite the achievement of remission after 6 mths of therapy,a loss of lean mass (probably the development of rheumatoid cachexia) continued in some pts, but these data need confirmation in studies with a large number of pts and a longer period of follow-up.

Disclosure of Interest: None declared

DOI: 10.1136/annrheumdis-2018-eular.575

\section{AB0413 NODULAR POLYARTERITIS AS AN UNFORESEEABLE ADVERSE REACTION IN RA PATIENT TREATED WITH TOFACITINIB}

Y. Muraviev ${ }^{1}$, S. Radenska-Lopovok ${ }^{2}$, V. Lebedeva ${ }^{1}$, S. Alamankina ${ }^{1} .{ }^{1}$ Federal State Budgetary Institution «Research Institute of Rheumatology» under the Russian Academy of Medical Sciences; ${ }^{2}$ I.M. Sechenov First Moscow State Medical University, Moscow, Russian Federation

Background: Tofacitinib basic prescribing information and guidelines for medica use do not provide any description of such adverse drug reaction (ADR) as vasculitis, in particular polyarteritis nodosa. We present a clinical case of vasculitis emerging during tofacitinib therapy.

Objectives: demonstration of an unexpected reaction to tofacitinib

Demonstration of an unexpected reaction to tofacitinib

Methods: A 59 y.o. RA female patient was hospitalised in December 2016 due to eruption of indurated nodules on her hips and legs producing sharp pain, ulceration of nodules on the legs, painful hip and ankle joints, and morning stiffness lasting for about one hour.

Results: Seropositive RA was diagnosed in this patient in April 2004 with subsequent DMARD with methotrexate (MT) at 7,5 mg/week. The remission achieved 